\title{
Assessment of Infection Control Knowledge Among Hemodialysis Patients in Kasr Al-Ainy Hospitals
}

\author{
MONA SOLIMAN, M.D.*; YASSIN S. IBRAHIM, M.D.*; NOHA A. OSMAN, M.D.**; \\ HODA I. RIZK, M.D.* and SALMA A. SEDDIK, M.Sc.* \\ The Departments of Public Health \& Community Medicine* and Internal Medicine**, Faculty of Medicine, Cairo University
}

\begin{abstract}
Background: Chronic Kidney Disease (CKD) is considered a public health issue. End-Stage Renal Disease (ESRD) is the form of CKD in which life can be sustained by dialysis or transplantation. In Egypt ESRD is one of the main health problems. Patients receiving Hemodialysis (HD) are at risk of acquiring infections as Hepatitis B Virus (HBV) and Hepatitis C Virus (HCV). As Devices used in dialysis units create an access site, Patients should be educated on how to keep the access site clean and dry and to recognize and report any signs and symptoms of infection immediately.

Aim of the Study: This study was conducted to assess the baseline knowledge in Infection Control (IC) among chronic HD patients and to detect rate of seroconversion from hepatitis $\mathrm{B} \&$ hepatitis $\mathrm{C}$ negative to positive among them.

Subjects and Methods: A cross sectional study design was conducted in the HD units at Kasr AlAiny hospitals. Patients with CKD stage $5 \mathrm{D}$ on regular HD participated in the study [two HD units are present in Kasr Al-Ainy Hospitals; 60 patients in unit (1) and 50 patients in unit (2)].

Results: Regarding the IC knowledge of the HD patients, the median total score was $6 / 10$ (4-10) in unit (1) and 6/10 (2-10) in unit (2). Regarding rate of seroconversion from $\mathrm{HCV}$ negative to HCV positive; in unit (1) one patient out of 65 was seroconverted in 2015. In unit (2); one patient out of 22 was seroconverted in 2014 , one patient out of 28 was seroconverted in 2015, and one patient out of 30 was seroconverted in 2016.

Conclusion: IC knowledge of chronic HD patients was generally low regarding the BSIs that they are at risk for, how to protect themselves and the IC practices that nurses should
\end{abstract} follow with them.

Key Words: Hemodialysis - Patients - Infection Control Knowledge - Seroconversion.

\section{Introduction}

CHRONIC Kidney Disease (CKD) is considered a public health issue. End-Stage Renal Disease

Correspondence to: Dr. Mona Soliman, The Department of Public Health \& Community Medicine, Faculty of Medicine, Cairo University
(ESRD) is the form of CKD in which life can be sustained by dialysis or transplantation [1] .

In Egypt ESRD is one of the main health problems as the estimated annual incidence is around 74 per million population (pmp) and the total prevalence of patients on dialysis is $264 \mathrm{pmp}$. The main Hemodialysis (HD) schedule implemented in Egypt is three sessions per week. All HD units, whether private or governmental, are supervised by the Egyptian Ministry of Health and Population (MOHP) [2] .

Patients receiving HD are at risk of acquiring infections due to exposure to invasive medical devices, immunosuppression, frequent close contact with other patients in the HD facility, and frequent hospitalizations. These infections include Methicillin-Resistant Staphylococcus Aureus (MRSA), Hepatitis B Virus (HBV) and Hepatitis C Virus (HCV) [3]

As Devices used in dialysis units create an access site, Patients should be instructed to keep the access site clean and dry and to recognize and report any signs and symptoms of infection immediately. The importance of personal hygiene and its possible relation to access site infections should be highlighted [4]

The Association for Professionals in Infection Control and Epidemiology (APIC) stated that one of the most important infection prevention measures is health education of HD patients and surveillance to measure infection rates [3]

Thus, the purpose of this study was to assess the IC knowledge among the HD patients as this will help in raising their IC awareness, reducing infections and improving the entire health status of the patients. 


\section{Subjects and Methods}

Study design: A cross sectional study design.

Study site and period: The study was conducted in the HD units at Kasr Al-Ainy Hospitals; Kasr Al-Ainy Kidney Center (KKC) and King Fahd Unit (KFU). It was conducted over a period of twelve months from April 2015 till April 2016. Regarding KKC; it recieves only chronic HD patients, it has one section for paid treatment and the other sections for patients treated on the expense of the state. Regarding KFU; it recieves both acute patients (peritoneal/Hemodialysis) and chronic HD patients, all sections for chonic patients are treated on the expense of the state while sections for acute patients are free of charge.

Study population: Patients with CKD stage 5D on regular HD attending both units. (Stage 5D or ESRD are chronic patients with kidney failure where the Glomerular Filtration Rate (GFR) is less than $15 \mathrm{~mL} / \mathrm{min} / 1.73 \mathrm{~m}^{2}$ and thus need permanent renal replacement therapy) [5]

All registered ambulatory chronic patients attending HD units from April 2015 till August 2015 were included; 60 patients in unit (1) and 50 patients in unit (2).

\section{Inclusion criteria:}

- Ambulatory chronic patients.

- Sex: Both males \& females.

- Age: Adults (above 18 years old).

\section{Study tools and data collection technique:}

Structured interview questionnaire for IC knowledge assessment of patients covering: Sociodemographic characteristics (e.g. age, sex, social class), full medical history (presence of comorbidities, infection with $\mathrm{HBV}$ or $\mathrm{HCV}$, immunization status) and 10 questions to test patients' basic IC knowledge (BSIs that they are at risk for, how to protect themselves, HBV immunization, isolation precautions, personal hygiene and the IC practices that nurses should follow with them). The questionnaire was designed based on the national guidelines for IC by MOHP [4] . It took 20-30 minutes to fulfill the questionnaire from each patient.

\section{Statistical analysis:}

The data was coded and entered using the statistical package SPSS version 21. The data was summarized using descriptive statistics; number and percentage for qualitative variables, and median, minimum and maximum values for quantitative variables which are not normally distributed. Statistical differences between groups were tested using Chi Square test, Mann-Whitney test and Kruskal-Wallis test. Correlation was done to test for linear relations between variables. $p$-values less than or equal to 0.05 were considered statistically significant.

Total score for patients was calculated as follow: Each patient achieved score 1 for correct answer, 0 for wrong answer then a total score for each patient was calculated, then all total scores of patients were summarized by median (min-max).

\section{Ethical considerations:}

Approval of the study protocol was obtained from the ethical committee at the Faculty of Medicine, Cairo University. Informed consent was obtained directly from each patient or his/her legal representative before enrolment and after explanation of the study objectives, the data confidentiality, as well as, the impact of the study. All the included patients were treated according to the Helsinki Declaration of biomedical ethics [6].

\section{Results}

IC Knowledge assessment chronic Hemodialysis patients:

Socio-demographic characteristics of chronic patients attending dialysis units (1) \& (2) at Kasr Al-Ainy Hospitals (Table 1):

Regarding dialysis unit (1); 60 patients were included in the study, $55 \%$ females $\& 45 \%$ males. The average age of patients was $(48.17 \pm 16.79$ years). More than half of the patients $(53.4 \%)$ were secondary and highly educated. Most of the patients $(61.7 \%)$ were from urban population. It was found that $85 \%$ of the patients don't work. The majority of the patients $(70 \%)$ were married.

Regarding dialysis unit (2); 50 were included in the study, $52 \%$ females \& $48 \%$ males. The average age of patients was ( $41.50 \pm 14.91$ years). Almost half of the patients (48\%) were secondary and highly educated. Most of the patients (62\%) were from urban population. It was found that $80 \%$ of the patients don't work. More than half of the patients $(56 \%)$ were married.

Medical history of chronic patients attending dialysis units (1) \& (2) at Kasr Al-Ainy Hospitals (Table 2):

Regarding dialysis unit (1); About $68 \%$ of the patients received previous dialysis sessions in other places. The majority of the patients $(81.7 \%)$ had comorbidities. Almost $28 \%$ of the patients were hepatic patients, most of them $(88.2 \%)$ acquired hepatitis virus after the HD treatment. Only $20 \%$ 
of the patients were vaccinated, more than half of them $(58.3 \%)$ were vaccinated before the HD treatment.

Regarding dialysis unit (2); Only $34 \%$ of the patients received previous dialysis sessions in other places. The majority of the patients $(80 \%)$ had comorbidities. About $44 \%$ of the patients were hepatic, most of them $(90.9 \%)$ acquired hepatitis virus after the HD treatment. Regarding HBV vaccine; $38 \%$ of the patients were vaccinated, most of them $(78.9 \%)$ were vaccinated after the HD treatment.

IC knowledge total scores of chronic patients attending dialysis units (1) \& (2) at Kasr Al-Ainy Hospitals (Table 3):

Regarding IC knowledge of patients; the median total score was $6(4-10)$ in unit (1) and 6 (2-10) in unit (2). Insignificant difference was found between them $(p=0.679)$.

Relation between median total score of chronic patients attending dialysis units (1) \& (2) at Kasr Al-Ainy Hospitals and socio-demographic characteristics (Table 4):

Regarding socio-demographic characteristics of patients; significant difference was found between education and median total score in unit (1) $(p=0.024)$ as well as unit $(2)(p=0.020)$, however all other characteristics (sex, residence \& occupation) showed insignificant differences.

Regarding the relation between age of patients and their median total scores in IC knowledge; no correlation was found in unit (1) ( $p$-value 0.255 , $r 0.149)$ as well as unit (2) ( $p$-value $0.752, r-0.046)$.

Relation between median total score of chronic patients attending dialysis units (1) \& (2) at Kasr Al-Ainy Hospitals and their medical history (Table 5):

Regarding medical history of patients, insignificant difference was found between median total score of patients and their medical history (previous dialysis sessions in other places, having comorbidities \& hepatitis virus infection) in unit (1) as well as unit (2).

Seroconversion of chronic Hemodialysis patients:

Reviewing the patients' serology records from January 2012 till the end of the study in April 2016 showed that: In unit (1), only 1 patient out of 65 (1.5\%) was seroconverted from $\mathrm{HCV}$ negative to HCV positive in July 2015. In unit (2), only 1 patient out of $22(4.5 \%)$ in January 2014 and 1 patient out of $28(3.6 \%)$ in July 2015 and 1 patient out of 30 (3.3\%) in March 2016 were seroconverted from $\mathrm{HCV}$ negative to $\mathrm{HCV}$ positive.

Despite having HBV positive patients in both units (1) and (2) (3 patients in each unit), no cases of seroconversion from $\mathrm{HBV}$ negative to $\mathrm{HBV}$ positive were detected.

Table (1): Socio-demographic characteristics of chronic patients attending dialysis units (1) \& (2) at Kasr Al-Ainy Hospitals.

\begin{tabular}{|c|c|c|c|c|}
\hline \multirow{2}{*}{ Item } & \multicolumn{2}{|c|}{ Unit (1) } & \multicolumn{2}{|c|}{ Unit (2) } \\
\hline & No. (60) & $\%$ & No. (50) & $\%$ \\
\hline \multicolumn{5}{|l|}{ Sex: } \\
\hline Male & 27 & 45.0 & 24 & 48.0 \\
\hline Female & 33 & 55.0 & 26 & 52.0 \\
\hline \multicolumn{5}{|l|}{ Educational Level: } \\
\hline Illiterate & 7 & 11.7 & 6 & 12.0 \\
\hline Read \& write & 8 & 13.3 & 4 & 8.0 \\
\hline Primary \& preparatory & 13 & 21.7 & 16 & 32.0 \\
\hline Secondary & 16 & 26.7 & 13 & 26.0 \\
\hline Highly educated & 16 & 26.7 & 11 & 22.0 \\
\hline \multicolumn{5}{|l|}{ Residence: } \\
\hline Rural & 23 & 38.3 & 19 & 38.0 \\
\hline Urban & 37 & 61.7 & 31 & 62.0 \\
\hline \multicolumn{5}{|l|}{ Occupation: } \\
\hline Fixed salary & 5 & 8.3 & 5 & 10.0 \\
\hline Changing salary & 4 & 6.7 & 5 & 10.0 \\
\hline Don't work & 51 & 85.0 & 40 & 80.0 \\
\hline \multicolumn{5}{|l|}{ Social Status: } \\
\hline Single & 13 & 21.7 & 16 & 32.0 \\
\hline Married & 42 & 70.0 & 28 & 56.0 \\
\hline Divorced & 1 & 1.7 & 3 & 6.0 \\
\hline Widow & 4 & 6.7 & 3 & 6.0 \\
\hline
\end{tabular}

Table (2): Medical history of chronic patients attending dialysis units (1) \& (2) at Kasr Al-Ainy Hospitals.

\begin{tabular}{|c|c|c|c|c|}
\hline \multirow{2}{*}{ Item } & \multicolumn{2}{|c|}{ Unit (1) } & \multicolumn{2}{|c|}{ Unit (2) } \\
\hline & $\begin{array}{l}\text { No. } \\
(60)\end{array}$ & $\%$ & $\begin{array}{l}\text { No. } \\
(50)\end{array}$ & $\%$ \\
\hline \multicolumn{5}{|c|}{$\begin{array}{l}\text { Previous dialysis sessions in } \\
\text { other places: }\end{array}$} \\
\hline Yes & 41 & 68.3 & 17 & 34.0 \\
\hline No & 19 & 31.7 & 33 & 66.0 \\
\hline \multicolumn{5}{|c|}{ Patients having comorbidities: } \\
\hline Yes & 49 & 81.7 & 40 & 80.0 \\
\hline No & 11 & 18.3 & 10 & 20.0 \\
\hline \multicolumn{5}{|c|}{$\begin{array}{l}\text { Patients infected with hepatitis } \\
\text { virus: }\end{array}$} \\
\hline Yes & 17 & 28.3 & 22 & 44.0 \\
\hline No & 43 & 71.7 & 28 & 56.0 \\
\hline \multicolumn{5}{|c|}{ Time of acquiring hepatitis } \\
\hline Before dialysis & 2 & 11.8 & 2 & 9.1 \\
\hline After dialysis & 15 & 88.2 & 20 & 90.9 \\
\hline \multicolumn{5}{|c|}{ Receiving $H B V$ vaccine: } \\
\hline Yes & 12 & 20.0 & 19 & 38.0 \\
\hline No & 48 & 80.0 & 31 & 62.0 \\
\hline \multicolumn{5}{|c|}{ Time of receiving $H B V$ vaccine: } \\
\hline Before dialysis & 7 & 58.3 & 4 & 21.1 \\
\hline After dialysis & 5 & 41.7 & 15 & 78.9 \\
\hline
\end{tabular}


Table (3): IC knowledge total scores of chronic patients attending dialysis units (1) \& (2) at Kasr Al-Ainy Hospitals.

\begin{tabular}{lccc}
\hline Total Score & Unit (1) & Unit (2) & $p$-value \\
\hline $\begin{array}{l}\text { Total score (10): } \\
\text { Median (min-max) }\end{array}$ & $6(4-10)$ & $6(2-10)$ & 0.679 \\
\hline
\end{tabular}

Table (4): Relation between median total score of chronic patients attending dialysis units (1) \& (2) at Kasr Al-Ainy Hospitals and socio-demographic characteristics.

\begin{tabular}{|c|c|c|}
\hline \multirow[t]{2}{*}{ Item } & $\begin{array}{c}\text { Unit (1) } \\
\text { Total score (10) }\end{array}$ & $\begin{array}{c}\text { Unit (2) } \\
\text { Total score (10) }\end{array}$ \\
\hline & Median (min-max) & Median (min-max) \\
\hline \multicolumn{3}{|l|}{$\begin{array}{l}\text { Socio-demographic } \\
\text { characteristics: } \\
\text { 1- Sex: }\end{array}$} \\
\hline Male & $6(4-10)$ & $6(3-9)$ \\
\hline Female & $7(4-9)$ & $7(2-10)$ \\
\hline$p$-value & 0.646 & 0.35 \\
\hline \multicolumn{3}{|l|}{ 2- Education: } \\
\hline Illiterate & $6(5-7)$ & $5(2-7)$ \\
\hline Read \& write & $7(6-9)$ & $6(5-7)$ \\
\hline $\begin{array}{l}\text { Primary \& } \\
\text { preparatory }\end{array}$ & $6(4-8)$ & $6(3-8)$ \\
\hline Secondary & $6(4-8)$ & $7(4-10)$ \\
\hline High education & $7.5(5-10)$ & $8(4-10)$ \\
\hline$p$-value & 0.024 & 0.02 \\
\hline \multicolumn{3}{|l|}{ 3-Residence: } \\
\hline Rural & $6(5-9)$ & $6(2-10)$ \\
\hline Urban & $6(4-10)$ & $7(2-10)$ \\
\hline$p$-value & 0.772 & 0.627 \\
\hline \multicolumn{3}{|l|}{ 4- Occupation: } \\
\hline Fixed salary & $7(4-10)$ & $8(5-10)$ \\
\hline Changing salary & $7(6-8)$ & $6(4-8)$ \\
\hline Don't work & $6(4-9)$ & $6(2-10)$ \\
\hline$p$-value & 0.391 & 0.226 \\
\hline
\end{tabular}

Table (5): Relation between median total score of chronic patients attending dialysis units (1) \& (2) at Kasr Al-Ainy Hospitals and their medical history.

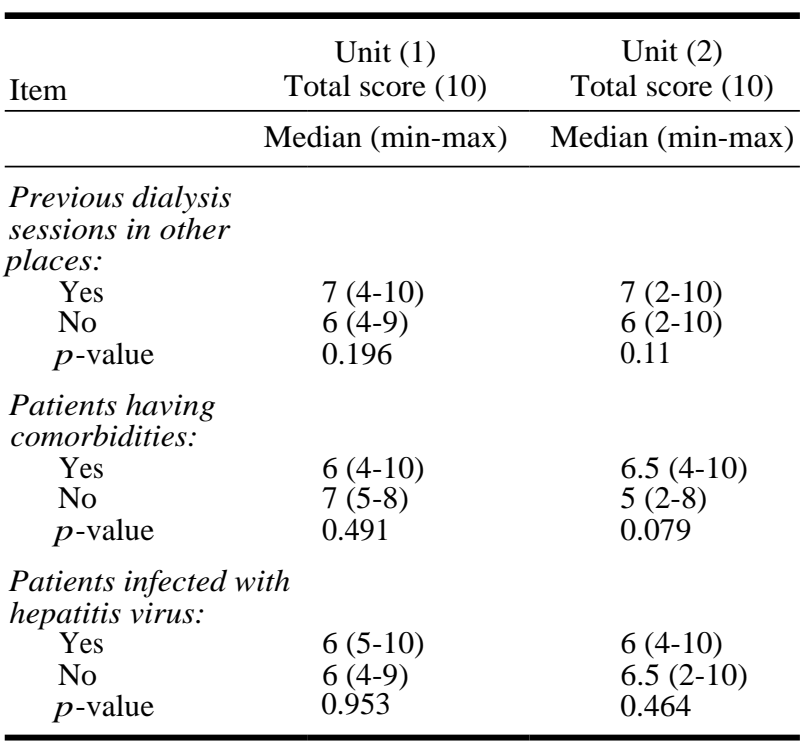

\section{Discussion}

Chronic HD patients are at risk of acquiring BSIs, and thus health education of patients remains a cornerstone in providing health care and plays an effective role in reducing HAIs. Therefore among the recommended strategies to reduce the risk of transmission of BSIs in HD units is educating patients about basic IC and how to protect themselves and their family members as well [7].

Accordingly this study was conducted aiming to reduce infections acquired within Kasr Al-Ainy dialysis units through assessing patients' knowledge and raising their IC awareness.

IC knowledge of the patients was generally low with a median total score 6/10 (4-10) in dialysis unit (1) and 6/10 (2-10) in unit (2) and this is logical as no health education sessions were conducted in both units also there weren't any health education materials present in the patients' area targeting the infections that can be transmitted in HD units, basic IC precautions or how the patients can protect themselves and their families.

In 2015 a study was conducted in Saudi Arabia mentioned that patients' health education in basic IC must be given upon admission to dialysis units and repeated at least yearly and should focus on the following topics: Personal hygiene, hand washing technique, vascular access care, infections that can be acquired, recognition of signs of infection and the vaccines they should take [8]

Regarding the relation between educational level of the patients and their median total scores it was statistically significant in dialysis unit (1) ( $p$-value 0.024) as well as unit (2) ( $p$-value 0.020). Highly educated patients were more knowledgeable in IC than patients with other educational levels as they achieved the highest scores; 7.5/10 (5-10) in unit (1) and 8/10 (4-10) in unit (2).

These results were consistent with a study conducted in Pakistan among HBV patients to assess their knowledge in IC. The average knowledge score of the patients was low 8.48/20 \pm 2.7 indicating that Hepatitis-B patients lack a basic understanding of IC which can lead to further spread of blood borne infections and that extensive health education campaigns should be provided routinely to the patients in the health care settings. Patients with high educational levels were more knowledgeable as graduates and post-graduates achieved average score $10.55 / 20 \pm 2$ which was significantly higher than the scores of other patients $(p=0.001)$ [9] 
The current results were consistent with a study conducted among Vietnamese Americans from community-based organizations who are at high risk of $\mathrm{HCV}$ infection. Educational program was implemented to raise their awareness towards $\mathrm{HCV}$ infection and their knowledge was assessed before and after their intervention. The average score in the baseline assessment was 3.3/10 \pm 2.6 and in the post-test was $5.9 / 10 \pm 2.6$ indicating a statistically significant improvement $(p<0.001)$. This reflected that health education could play an important role in increasing knowledge related to HCV and ultimately reduce the HCV knowledge disparity in the vulnerable population [10]

The current study showed that the last recorded seroconversion rate was in $(3.3 \%)$ in 2016 in one of the HD units which is relatively high. This could be attributed to the improper implementation of isolation precautions in the HD units.

These results were consistent with a study conducted in HD units in Qalyubia Governorate which showed that the seroconversion rate of hepatitis was $4 \%$. This reinforces the utmost importance of testing all the patients for $\mathrm{HCV}, \mathrm{HBV}$, and HIV before admission to dialysis unit, introducing the immunization policy of HBV, implementing the isolation policy, screening the patients as well as the HCWs for HCV, HBV, and HIV every 3-6 months and compliance of HCWs to standard precautions of IC [11].

The current results were also compared with a study conducted in Moroccan HD units which showed that the incidence of seroconversion was 0.9 per 100 patients/year. These excellent results reflected the continuous application of universal rules of hygiene as well as isolation policy and the strict compliance of $\mathrm{HCW}$ s to standard precautions of IC [12]

Finally, the current study emphasized that improving the patients' knowledge is the second arm for reducing Healthcare Associated Infections (HAIs) together with HCWs' compliance to IC measures.

\section{Conclusion:}

IC awareness among chronic HD patients was generally low regarding the BSIs that they are at risk for (HBV, HCV \& HIV), how to protect themselves \& their families and the basic IC practices that HCWs should follow with them.

\section{Recommendations:}

- Conducting regular health education sessions to chronic HD patients on different health topics (infections that could be acquired in hospitals, how to perform hand hygiene etc....).

-All HD patients should be fully immunized against HBV infection.

- Routine virology test (HBV, HCV, HIV) should be done for all HD patients every 3-6 months.

- Surveillance of HAIs and mainly BSIs within HD units and detecting rates of seroconversion.

- Recommendation for further research concerning:

- Evaluation of IC knowledge among patients in other clinical settings.

\section{References}

1- SCHOOLWERTH A.C., ENGELGAU M.M., HOSTETTER T.H., RUFO K.H., CHIANCHIANO D., MCCLELLAN W.M., WARNOCK D.G. and VINICOR F.: Chronic Kidney Disease: A Public Health Problem That Needs a Public Health Action Plan. Preventing Chronic Disease, 3: A57, 2006.

2- AHMED A.M., ALLAM M.F., HABIL E.S., METWALLY A.M., IBRAHIEM N.A., RADWAN M., EL-GAAFARY M.M., AFIFI A. and GADALLAH M.A.: Development of practice guidelines for hemodialysis in Egypt. Indian Journal of Nephrology, 20: 193-202, 2010.

3- REBMANN T. and BARNES S.A.: Preventing infections in hemodialysis: An executive summary of the APIC: Elimination Guide. American Journal of Infection Control, 39: 72-75, 2011.

4- MOHP: National guidelines for Infection Control: Part II: Infection Control in Specialty Settings: Dialysis. Retrieved on 19-12-201 3 from:http://www.drguide. mohp.gov.eg/NewSite/e-learning/Infection Control/ infctrlp2.asp, 2008a.

5- National Kidney Foundation: Glomerular Filtration Rate (GFR). Retrieved on 5-8-2016 from: https://www.kidney. . org/atoz/ content/gfr, 2015.

6- World Medical Association Declaration of Helsinki: Ethical Principles for Medical Research Involving Human Subjects. Revised by the $59^{\text {th }}$ WMA General Assembly, Seoul, Republic of Korea. Retrieved on 17-12-2013 from: http://www.wma.net/en/30publications/10policies/b3/, 2008.

7- SEE I., SHUGART A., LAMB C., KALLEN A.J., PATEL P.R., RONDA L. and SINKOWITZ-COCHRAN R.L. Infection Control and Bloodstream Infection Prevention: The Perspective of Patients Receiving Hemodialysis. Nephrology Nursing Journal, 41 (1): 37-40, 2014.

8- Alkhan A.A.: Hepatitis B Virus (HBV) and Hepatitis C Virus (HCV) Infections among Hemodialysis Patients. General Medicine (Los Angel), 3: 165, 2015.

9- UL HAQ N., HASSALI M.A., SHAFIE A.A., SALEEM F., FAROOQUI M., HASEEB A. and ALJADHEY H.: A cross-sectional assessment of knowledge, attitude and practice among Hepatitis-B patients in Quetta, Pakistan. BMC Public Health, 13: 448, 2013.

10- LEE S., ZHAI S., ZHANG G., MA X.S., LU X., TAN Y., SIU P., SEALS B. and MA G.X.: Factors Associated with Hepatitis C Knowledge Before and After an Educational Intervention among Vietnamese Americans. Clinical Medicine Insights Gastroenterology, 8: 45-53, 2015. 
11- AHMED KHAMIS S.S., EL-AZIZ KORA M.A., ELBARBARY H.S. and GHARIB S.M.: Assessment of safety measures in hemodialysis units in Qalyubia Governorate. Menoufia Medical Journal, 30: 672-678, 2017.
12- ABDELAALI B., OMAR M., TAOUFIK D., SAMIR A and SAAD M.: Hepatitis $C$ viral prevalence and seroconversion in Moroccan hemodialysis units: Eight year followup. J. Med. Diagn. Meth., 2: 141, 2013.

\section{تقييـم معرفة مرضى الغسيل الكلوى بمكافحة العلدوى

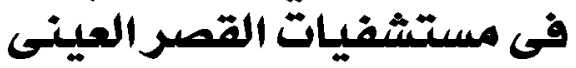

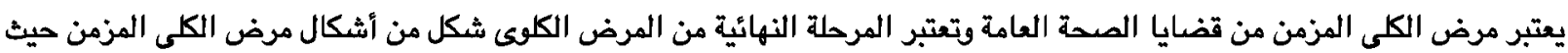

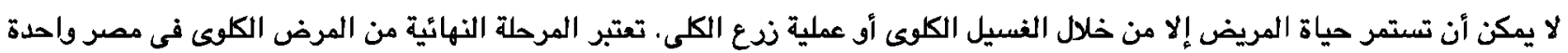

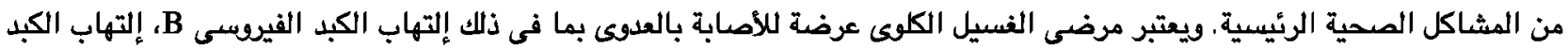

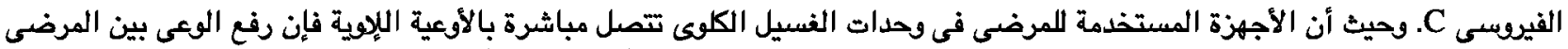

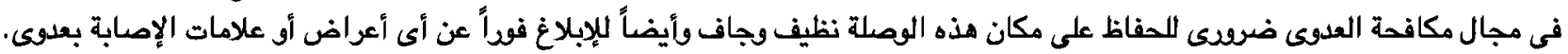

وقد أجريت هذه الدراسة لتقييم المعرفة الأساسية للى مرضى الغسيل الكلوى المزمن فى مكافحة العدوى قأيضاً للكثف عن معدل التحل

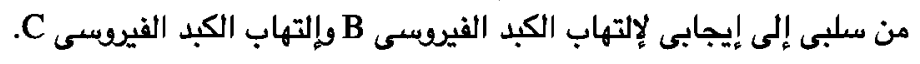

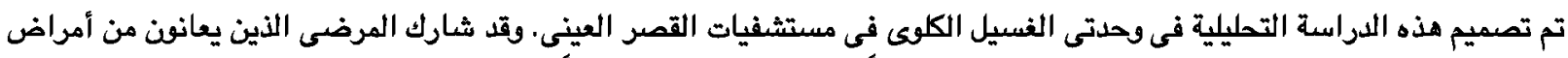

الكلى المزمنة مرحلة 5D على الغسيل الكلوى المنتظم، 60 مريضاً فى وحدة (1) و. ـه مريضاً في وحدة (2).

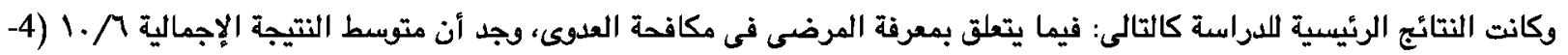

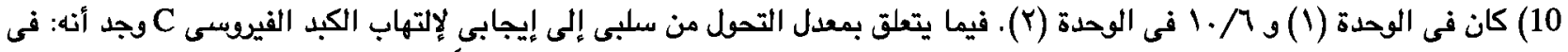

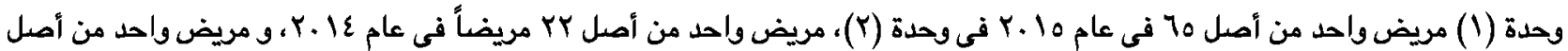

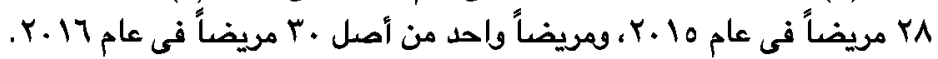

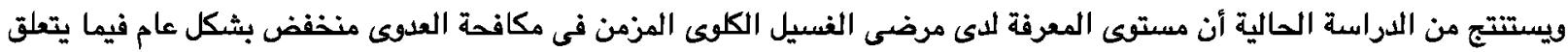

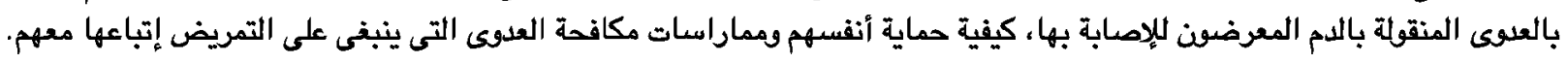

